\title{
Perspectivas metodológicas para a identificação do aboutness em textos narrativos de ficção
}

\author{
Perspectivas metodológicas para la identificación de la tematicidad en los textos narrativos de ficción
}

Methodological perspectives for aboutness identification on fiction narrative texts

\author{
João Batista Ernesto de MORAES \\ Faculdade de Filosofia e Ciências, Universidade Estadual Paulista, Campus de Marília. \\ Avenida Hygino Muzzi Filho, 737, Marília, SP, Brasil. CEP: 17525-900, jota@marilia.unesp.br
}

\begin{abstract}
Resumen
Propuesta de utilización teórica y metodológica del recorrido generativo de sentido postulado por Greimas con la intención de desarrollar una metodología para la identificación de conceptos en textos narrativos de ficción de cara a su indización temática.
\end{abstract}

Palabras clave: Análisis documental de contenido. Tematicidad. Recorrido generativo de sentido. Texto narrativo de ficción.

\section{Considerações iniciais}

A ênfase da Análise Documental quanto à análise do documento científico como o paradigma documental para o tratamento de conteúdo se encontra amplamente difundida na tradição da Biblioteconomia, da Documentação e da Ciência da Informação enquanto fundamentação de seus procedimentos técnicos. Neste sentido, não apenas a tradição francesa de $A D$, mas também os estudos de classificação e de indexação têm seu foco no texto científico, visualizando-o como paradigma de suporte de informação.

Contudo, García-Marco et al. (2010) chamam a atenção para outros aspectos que começam a se fazer presentes.

The revolution of today is about multimedia information, and a great deal of such information does not suit into the frame of traditional scientific reports and articles. They are much nearer to fiction and narrative documents. In fact, narrative-based communications are gaining considerable room in disciplines like education-with multimedia and video as increasing important tools in face-to-face, blended and virtual education-, psychology and even in fields like business and management in general, where the "story-telling" movement is gaining importance in marketing, corporative culture management and political communication. (GarcíaMarco et al., 2010, p. 395)

\begin{abstract}
Proposal of a theoretical and methodological use of the generative meaning trajectory postulated by Greimas with the intention of developing a methodology for the identification of concepts in narrative texts of fiction to facilitate its subject indexing and classification.
\end{abstract}

Keywords: Document analysis. Aboutness. Generative meaning trajectory. Narrative texts of fiction.

Com relação à afirmação que os estudos tradicionais sempre enfocaram os documentos científicos, entretanto, Eriksson (2005) faz a seguinte ressalva:

\begin{abstract}
Although it often may seem so, the classification and indexing of imaginative literature and fiction in particular is not an issue that has only been discussed in the last few decades. Presumably the first serious article on the subject appeared in 1898, when the noteworthy British librarian Ernest Baker wrote about the classification of fiction in the Library World (Baker, 1898), and in the beginning of the $20^{\text {th }}$ century a prolonged discussion concerning the same issue took place in the American Library Association (ALA) after John Thomson had initiated a major fiction classification project at the Wagner Institute Branch of the Free Library of Philadelphia. (Eriksson, 2005, p. 01).
\end{abstract}

A rigor, nos últimos trinta anos, a questão dos textos literários parece ter voltado à tona, pois podem ser encontrados os estudos de Pejtersen (1978, 1979, 1983, 1984,1998), Beghtol (1986, 1992, 1994, 1995, 1997), Hayes (1992), Nielsen (1997), Saarti (1999), García-Marco e GarcíaMarco (1997), dentre outros. Porém, deve-se observar que tais estudos concentram seu foco nas questões de indexação, classificação ou recuperação da informação, ou seja, as preocupações recaem antes sobre a questão dos produtos documentais, do que sobre a questão da análise do documento, tal como preconizado pela $A D$. 
Deve-se acrescentar, ainda, que tais produtos documentais, em sua maioria, focam a questão do gênero (romance, poesia, drama), da nacionalidade (Romance Inglês, Romance Brasileiro, Romance Espanhol), ou mesmo rotulado sob o genérico "ficção".

E é exatamente o foco no documento e em seu processo de análise que interessa particularmente a este estudo, uma vez que se pretende privilegiar o estudo do próprio documento literário como forma de se obter o conteúdo temático dos documentos.

Além disso, deve-se observar que o documento que é objeto da $A D$, notadamente em bibliotecas, não é apenas o documento científico, pois em algumas dessas unidades de informação, tais como Bibliotecas Públicas e Bibliotecas Escolares, o texto narrativo é objeto de especial atenção, seja no desenvolvimento de coleções, seja na organização das mesmas para atender ao usuário. Além destas bibliotecas, deve-se ter em mente, também, as Bibliotecas Universitárias, notadamente da área de Letras, as quais abrigam um grande acervo de textos narrativos que, por sua vez, necessita ser precisa e objetivamente tratado como suporte ao ensino e à pesquisa em seus cursos de Graduação e PósGraduação.

Porém, no momento em que a "matéria prima" da $A D$ consiste em textos narrativos de ficção, a complexidade aumenta consideravelmente, pois o modelo metodológico de identificação de conceitos elaborado para textos científicos, pautado na leitura documental de partes canônicas do texto, tais como título, subtítulo, resumo, etc. (Chaumier, 1988), não se aplica a textos narrativos, pois a estrutura destes textos assume outras formas de evidenciar seu conteúdo.

Este estudo tem o objetivo de fazer uma proposta de análise de textos narrativos de ficção a partir do Percurso Gerativo de Sentido com vistas à identificação do aboutness e dos meanings.

Esta proposta parte do pressuposto que as metodologias disponíveis para a análise de textos científicos não é adequada para textos narrativos de ficção, dadas as diferenças entre ambos, bem como demonstram estudos anteriores sobre a análise deste último tipo de textos, como pode ser visto em Guimarães, Moraes e Guarido (2007), Moraes (2008), e em Moraes e Guimarães $(2006,2008)$.

Para tanto, será feito o cotejamento de alguns procedimentos já apresentados na literatura acima citada.

\section{A questão do Aboutness}

Em artigo publicado no de 2006, Moraes; Guimarães (2006) davam os primeiros passos no sentido de estabelecer ligações entre 0 aboutness/meaning e Percurso Gerativo de Sentido. Segundo os autores, o texto partia do resgate teórico das concepções de aboutness como suporte à análise documental em documentos científicos e, em seguida, buscava-se caracterizar o texto narrativo em sua estrutura de conteúdo, privilegiando-se os percursos temático e figurativo.

Com base em tais elementos, foi desenvolvida uma análise comparativa das dimensões de aboutness e meaning previstas por Beghtol, com os percursos temático e figurativo abordados por Greimas, de modo a estabelecer o cotejo entre os traços distintivos de ambas as teorias. Por fim, chegou-se à conclusão que um ponto em comum unia estas duas concepções teóricas: a delimitação específica do conteúdo do documento. (Moraes e Guimarães, 2006, p. 74).

Beghtol (1986) expõe o seu ponto de vista nos seguintes termos:

Whatever terms are chosen, a distinction between 'aboutness' and 'meaning', as the terms used here, seems justifiable on the assumption that a document has an intrinsic subject, an 'aboutness', that is at least to some extent independent of the temporary usage to which an individual might put one or more of its meanings. (Beghtol, 1986, p. 85).

Sintetizando esses dois níveis de conteúdo informacional, Beghtol (1986, p. 85) refere-se a um aboutness propriamente dito, e a um meaning. Assim, tem-se, segundo a autora, o aboutness como algo intrínseco ao documento, de natureza relativamente permanente, integrando a essência do mesmo, ao passo que o meaning é mutável em função do local, do momento histórico, do interesse do usuário, etc.

\section{Escolha do corpus de análise}

Para a realização deste estudo, optou-se pelo texto usado por Moraes e Guimarães (2006, 2008) para que se pudesse ter um parâmetro de comparação entre os estudos empreendidos por aqueles autores e o atual. Trata-se do texto Mudanças imutáveis, de autoria de Millôr Fernandes. Acerca das estruturas do discurso das fábulas, são colocados "em cena personagens que dramatizam ações humanas, ela incluirá nessas ações as paixões e sentimentos negativos e positivos, que permeiam as atitudes dos humanos" (Quinelato, 2009, p.30). 
Desta forma, este tipo de texto interessa ao presente estudo, pois estão em jogo personagens que estarão 'jogando um jogo', com intenção de se extrair certa moral.

Mudanças Radicais Imutáveis À maneira dos... Chineses (Fernandes, s. d.)

01 Olin-Pin, abastado negociante de óleos e arroz,

02 vivia numa imponente mansão em Kin-Tipê. A

03 sua posição social e a sua mansão só não eram

04 perfeitas porque, à direita e à esquerda da

05 propriedade, havia, há algum tempo, dois

06 ferreiros que ferreiravam ininterruptamente,

07 tinindo e retinindo malhos, bigornas e

08 ferraduras.

09 Olin-Pin, muitas vezes sem dormir, dado o tim-

10 pin-tin, pan-tan-pan a noite inteira, resolveu

11 chamar os dois ferreiros, e ofereceu a eles 1000

12 iens de compensação, para que ambos se

13 mudassem com suas ferrarias. Os dois ferreiros

14 acharam tentadora a proposta (um ien, na

15 época, valia mil euros) e prometeram pensar no

16 assunto com todo empenho.

17 E pensaram. E com tanto empenho que, apenas

18 dois dias depois, prevenidamente

19 acompanhados de oito advogados,

20 compareceram juntos diante de Olin-Pin. E

21 assinaram contrato, cada um prometendo se 22 mudar para outro lugar dentro de 24 horas. Olin-

23 Pin pagou imediatamente os 1000 iens (que a

24 essa altura já eram 10.000) prometidos a cada

25 um e foi dormir feliz, envolvido em lençóis de

26 seda e adorável silêncio. Mas no dia seguinte

27 acordou sobressaltado, os ouvidos estourando

28 com o mesmo barulho de sempre.

29 E, quando ia reclamar violenta e legalmente

30 contra a quebra de contrato, verificou que não

31 tinha o que reclamar. Os dois ferreiros tinham

32 cumprido fielmente o que haviam prometido.

33 Ambos tinham se mudado. O ferreiro da direita

34 tinha se mudado pra esquerda e o da esquerda

35 tinha se mudado pra direita.

36 Moral: Cuidado quando a esquerda e a direita

37 estão de acordo.

\section{Quadro I. Texto analisado}

Por fim, deve-se ressaltar que para este estudo foi utilizada uma versão online com algumas modificações introduzidas pelo autor. Isto ocorre porque a versão online utilizada por Moraes e Guimarães $(2006,2008)$ não estava mais disponível para consulta. Deve-se ressaltar, porém, que as mudanças introduzidas pelo autor, inclusive no título (passou de Mudanças Imutáveis para Mudanças Radicais Imutáveis) não tiveram o condão de alterar substancialmente o conteúdo do texto, não redundando, portanto, em alterações na análise feita.

\section{Procedimentos de análise}

Nesta seção serão discutidos os procedimentos de análise de textos narrativos de ficção, com vistas à identificação do aboutness e dos meanings. O primeiro procedimento envolve a identificação do texto narrativo. Num segundo momento, serão feitos procedimentos para se atestar que o texto pode ser classificado como um texto narrativo de ficção. Na sequência, proceder-se-á à análise do texto conforme os três patamares preconizados no Percurso Gerativo de Sentido, ou seja, serão investigadas as estruturas profunda, narrativa, e discursiva.

Por fim, terminada a análise, será possível verificar se o Percurso Gerativo de Sentido foi capaz de indicar o aboutness e os meanings do texto analisado.

A rigor, os processos de Análise Documental de Conteúdo principiam com uma leitura técnica pelo analista. Porém, dada a peculiaridade dos textos ora em análise, textos narrativos de ficção, optou-se por não discutir a questão da leitura, haja vista que há ampla literatura a respeito (1).

\subsection{Procedimentos de análise} para identificação do texto narrativo

Embora não se encontre em Moraes e Guimarães $(2006,2008)$ nenhuma recomendação a respeito, deve-se ressaltar que Guimarães, Moraes e Guarido (2007) propõem a indicação da seguinte sequência para a identificação do texto narrativo, baseado nos princípios teóricos de Van Dijk (1997) e Koch e Fávero (1987):

- Superestrutura: predomínio das ações; sequência de acontecimentos que envolvem a complicação, a avaliação e a resolução.

- Macroestrutura: presença de personagens, seres animados, ou algo definido antropologicamente; pressupõe uma ideia de ação, de mudança de estado, de transformação ou acontecimentos; a sequência temporal é fundamental.

- Dimensão linguística de superfície: verbos que indicam mudanças no passado, e indicadores de tempo e lugar.

Desta forma, o analista deve principiar o seu processo de análise por uma leitura do texto em busca dos elementos descritos acima.

Baseado nos critérios acima, e após uma primeira leitura do texto, montou-se o quadro II para avaliar-se se o texto ora em análise pode ser considerado um texto narrativo: 


\begin{tabular}{|c|c|}
\hline Critérios & Descrição \\
\hline Superestrutura & $\begin{array}{l}\text { Pode-se atestar uma } \\
\text { sequência de ações } \\
\text { manifestadas pela presença } \\
\text { dos seguintes elementos: } \\
\text { - complicação: Ferreiros } \\
\text { perturbam o sono de Olin-Pin } \\
\text { (linhas } 1 \text { a 20); } \\
\text { - avaliação: O comerciante } \\
\text { paga para os ferreiros se } \\
\text { mudarem (linhas } 20 \text { a } 26 \text { ); } \\
\text { - resolução: os ferreiros se } \\
\text { mudam (linhas } 26 \text { a } 35 \text { ).. }\end{array}$ \\
\hline Macroestrutura & $\begin{array}{l}\text { Podem ser atestados os } \\
\text { seguintes elementos: } \\
\text { - Presença de personagens: } \\
\text { Olin-Pin , ferreiro da direita, } \\
\text { ferreiro da esquerda, } 8 \\
\text { advogados } \\
\text { - Sequência temporal: Há um } \\
\text { antes - os ferreiros perturbam } \\
\text { o sono do comerciante (linhas } \\
1 \text { a } 20 \text { ); um durante - os } \\
\text { ferreiros aceitam se mudar } \\
\text { (linhas } 20 \text { a } 26 \text { ); e um depois - } \\
\text { os ferreiros se mudam (linhas } \\
26 \text { a 35). }\end{array}$ \\
\hline $\begin{array}{l}\text { Dimensão } \\
\text { linguística } \\
\text { de superfície }\end{array}$ & $\begin{array}{l}\text { Podem ser encontrados verbos } \\
\text { que indicam mudanças no } \\
\text { passado: compareceram (linha } \\
\text { 20); assinaram (linha 21); } \\
\text { pagou (linha 23); tinham se } \\
\text { mudado (linha 33); bem como } \\
\text { indicação de tempo e lugar: } \\
\text { Kin-Tipê (linha 01); à direita e } \\
\text { à esquerda (linha 02); no dia } \\
\text { seguinte (linha 26). }\end{array}$ \\
\hline
\end{tabular}

Quadro II. Conferência dos critérios do texto narrativo

Considerando-se que todos os critérios foram cumpridos, pode-se atestar que o texto ora em análise pode ser definido como um texto narrativo. Pode-se até afirmar que a experiência do analista enquanto falante de uma determinada comunidade linguística pode levá-lo, de forma empírica, a identificar um texto narrativo. Porém, considerando que há textos que podem apresentar dúvidas, e também por não ser um procedimento científico, recomenda-se a leitura atenta do texto em busca dos elementos caracterizadores do texto narrativo.

\subsection{Procedimentos de análise para identifica- ção do texto narrativo de ficção}

Considerando que a ficção é uma forma de manifestação artística, na qual o artista se serve das palavras para criar a sua obra de arte, o analista deve buscar elementos que possam caracterizar o texto como fiç̧ão.

Deve-se ressaltar que tais caracterizações sempre serão arbitrárias, haja vista a falta de consenso sobre o que seja ficção $x$ não-ficção. Mesmo na área de Comunicação Social, na qual é esperada a predominância do não-ficcional, há tempos trava-se um debate sobre os limites, as diferenças, e as interrelações entre o texto jornalístico e o texto literário.

No texto de Millôr Fernandes, pode-se notar a o uso de elementos poéticos desde o título da fábula. $\mathrm{O}$ uso da expressão Mudanças radicais imutáveis pode ser classificada como um oximoro (Moisés, 2009. p. 332), tendo em vista a reunião de dois termos que são paradoxais, e que se excluem mutuamente, como no célebre soneto de Camões - Fogo que arde sem se ver/Ferida que dói e não se sente/Contentamento descontente.

Além disso, o autor apela para a sonoridade de alguns nomes para sugerir tanto a nacionalidade de um personagem (Olin-Pin - Linha 01), tanto quanto lugares exóticos (Kin-Tipé - Linha 02). Aparentemente, não há nenhuma correspondência entre estes nomes listados pelo autor e eventuais pessoas e locais chineses. Aliás, em nenhum momento o texto deixa transparecer que o local dos acontecimentos é a China, apenas há uma referência ao dinheiro adotado naquele país - o ien, que pode sugerir que ação por lá se desenrola.

Ainda trabalhando a questão da sonoridade, pode-se perceber que há o uso das onomatopeias (2) como que para ilustrar o trabalho dos ferreiros, como pode ser visto nas linhas 09 e 10: tim-pin-tin, pan-tan-pan.

Por fim, há que se registrar, ainda a presença de neologismos no texto, como o verbo ferreiravam, que aparece na linha 06 . O autor utiliza-se do substantivo ferreiro para criar um verbo que indica a atividade deste profissional.

Desta forma, considerando-se a presença destes elementos, pode-se afirmar que o texto ora em análise é um texto narrativo de ficção, pois há forte presença da função poética no texto.

\subsection{Procedimentos de análise para aplicação do Percurso Gerativo de Sentido}

Nesta etapa, o analista se confrontará com a construção do Percurso Gerativo de Sentido, levando em consideração os três patamares: as estruturas fundamentais, as estruturas narrativas e as estruturas discursivas (Moraes e Guimarães, 2006, p. 78; 2008, p. 40). 
A rigor, os autores propõem que se inicie a análise pelas estruturas fundamentais, sendo esta conceituada como as "categorias semânticas que ordenam os conteúdos do texto de maneira mais geral e mais abstrata" (Moraes e Guimarães, 2008, p. 40). Porém, os procedimentos de Análise Documental fazem o percurso de maneira diferente, buscando, por fim, chegar às categorias mais abstratas do documento, o que pode ser chamado de aboutness. Desta forma, para este estudo, por uma questão de coerência com a opção feita pela depreensão do aboutness (3), proceder-se-á à análise das estruturas narrativas (4), das estruturas discursivas (5), para, então, se chegar à análise das estruturas fundamentais, esperando-se que, a partir destas, chegue-se ao aboutness e aos meanings.

\subsubsection{Procedimentos de análise das estruturas narrativas}

Para a análise das estruturas narrativas, Moraes e Guimarães (2008, p. 39) chamam a atenção para a questão das chamadas estruturas canônicas:

Na manipulação, um sujeito transmite a outro um querer ou dever, concretizados em forma de súplica, pedido, ordem, etc. Na competência, um sujeito atribui a outro um saber e um poder fazer. Na performance, há a transformação principal da narrativa. Por último, na sanção cognitiva há o reconhecimento de que a competência se realizou, e a sanção pragmática pode ou não ocorrer, manifestando prêmios e castigos.

\section{Manipulação}

01 Olin-Pin, abastado negociante de óleos e arroz, 02 vivia numa imponente mansão em Kin-Tipê. A 03 sua posição social e a sua mansão só não eram 04 perfeitas porque, à direita e à esquerda da 05 propriedade, havia, há algum tempo, dois 06 ferreiros que ferreiravam ininterruptamente, ti07 nindo e retinindo malhos, bigornas e ferraduras.

08 Olin-Pin, muitas vezes sem dormir, dado o tim09 pin-tin, pan-tan-pan a noite inteira, resolveu 10 chamar os dois ferreiros, e ofereceu a eles 1000

11 iens de compensação, para que ambos se 12 mudassem com suas ferrarias. Os dois ferreiros 13 acharam tentadora a proposta (um ien, na 14 época, valia mil euros) e prometeram pensar no 15 assunto com todo empenho.

\section{Quadro III. Manipulação}

Os autores ainda destacam que a sequência canônica não pode implicar necessariamente num formato pré-definido, segundo o qual todos os textos narrativos devem se encaixar, como se fosse uma fórmula ao qual o ficcionista tivesse que se adequar (6), mas, ao contrário, algumas fases podem apenas ser pressupostas, ou implícitas, ou ter um destaque maior do que as outras. (Moraes e Guimarães, 2008, p. 39).

Desta forma, uma nova leitura do texto torna-se necessária, com o intuito de se detectar os elementos das estruturas narrativas, principiandose pela manipulação. A análise, ora levada a cabo, coincidiu com a análise feita por Moraes e Guimarães (2008), pois detectou a manipulação entre as linhas 01 e 15, como pode ser visto no quadro III: Considerando-se que a manipulação pode ser caracterizada como a transmissão de um querer ou dever, concretizados em forma de súplica, pedido, ordem, etc., pode-se verificar que, na passagem assinalada, o comerciante propõe aos dois ferreiros que se mudem, em troca de uma vultosa recompensa, caracterizando, assim a manipulação. Depois de detectada a manipulação, o analista deve continuar com a detecção dos demais elementos, no caso a competência e a performance. A análise do texto com relação à competência e à performance não foi coincidente, porém, com a análise de Moraes e Guimarães (2008, p. 42), conforme pode ser percebido no quadro IV:

\section{Competência}

16 E pensaram. E com tanto empenho que, apenas

17 dois dias depois, prevenidamente acompanha-

18 dos de oito advogados, compareceram juntos

19 diante de Olin-Pin. E assinaram contrato, cada

20 um prometendo se mudar para outro lugar den-

21 tro de 24 horas. Olin-Pin pagou imediatamente

22 os 1000 iens (que a essa altura já eram 10.000)

23 prometidos a cada um e foi dormir feliz, envolvi-

24 do em lençóis de seda e adorável silêncio.

\section{Quadro IV. Competência}

$\mathrm{Na}$ análise da competência e da performance, como dito, não houve coincidência com a análise de Moraes; Guimarães (2008, p. 42). Para os autores, o trecho que vai da linha 16 à linha 24 é considerado como performance. Entretanto, deve-se ressaltar que os autores não comentam as razões das suas análises.

Já a análise ora em questão considerou-se que há, no trecho acima destacado há uma atribuição de um poder fazer, ou seja, o comerciante dá dinheiro aos ferreiros para que estes se mudem para longe de sua casa com as respectivas ferrarias. Considera-se, também, que a performance está inserida na sanção, pois é nesta última que se revela a transformação ocorrida na narrativa. 
Por fim, deve o analista desenvolver a análise da porção final do texto, que pode ensejar em uma sanção cognitiva ou uma sanção pragmática, como visto anteriormente.

Pela análise, pode-se concluir que houve uma sanção pragmática, como pode ser vista no quadro $\mathrm{V}$ :

\section{Sanção}

25 Mas no dia seguinte acordou sobressaltado, os

26 ouvidos estourando com o mesmo barulho de

27 sempre.

$28 \mathrm{E}$, quando ia reclamar violenta e legalmente

29 contra a quebra de contrato, verificou que não

30 tinha o que reclamar. Os dois ferreiros tinham

31 cumprido fielmente o que haviam prometido.

32 Ambos tinham se mudado. O ferreiro da direita

33 tinha se mudado pra esquerda e o da esquerda

34 tinha se mudado pra direita.

35 Moral: Cuidado quando a esquerda e a direita

36 estão de acordo.

\section{Quadro V. Sanção}

Como afirmado, pode-se perceber que a principal mudança está inserida na própria sanção, ou seja, a mudança das ferrarias, que era esperada, realmente ocorre, mas não da maneira que se esperava. De fato, os ferreiros se mudaram, mas apenas trocando de lado. A rigor, pode-se questionar se houve realmente a mudança almejada pelo comerciante, pois ele, certamente, continuará incomodado pelo baruIho oriundo das ferrarias. De certa forma, a sanção, no presente caso, manifesta-se como um castigo infligido ao comerciante e que já se prenuncia no título, ou seja, as tais mudanças radicais imutáveis.

Concluída a parte de identificação das estruturas narrativas, deve o analista, na sequência, passar para a análise das estruturas discursivas. Para tanto deve o analista fazer a descrição do percurso temático e do percurso figurativo, como se verá na a seguir, tendo como ponto de partida a análise já feita das estruturas narrativas.

\subsubsection{Procedimentos de análise das estruturas discursivas}

No terceiro nível de análise aparecem as estruturas narrativas abstratas, as quais podem ser concretizadas através da figurativização ou da tematização, ou seja, através de temas ou figuras. (Moraes e Guimarães, p. 40).

Para tanto, há que se verificar qual é predominância que existe no texto, elementos concretos (figuras) ou elementos abstratos (temas), com o intuito de se verificar de que forma ocorre a interação entre estes elementos, ou seja, de que maneira se verifica o percurso temático ou o percurso figurativo, sempre tendo em mente que concreto e abstrato não são termos polares que se opõe mutuamente, mas sim constituem um continuum em que se vai, de maneira gradual, do mais abstrato ao mais concreto.

Moraes e Guimarães (2008) apresentam as seguintes análises dos percursos temático e figurativo, realizados a partir de cada um dos elementos das estruturas narrativas:

\begin{tabular}{ll}
\hline & Manipulação \\
\hline Temas & Figuras \\
\hline Posição social & negociante de óleos e arroz \\
\hline $\begin{array}{l}\text { não era(m) } \\
\text { perfeitas }\end{array}$ & Imponente mansão \\
\hline Resolveu & dois ferreiros \\
\hline Ofereceu & $\begin{array}{l}\text { ferreiravam } \\
\text { ininterruptamente }\end{array}$ \\
\hline & sem dormir \\
\hline 1000 iens \\
\hline Mudassem \\
com suas ferrarias \\
\hline Pemas & Competência \\
\hline Pensaram & Figuras \\
\hline Acompanhados \\
de advogados \\
\hline Eumente
\end{tabular}

Quadro VI. Temas e figuras na manipulação, performance e sanção

(Moraes e Guimarães, 2008, p. 43) 
Deve-se destacar que os autores não detalham quais foram os procedimentos utilizados para a extração dos temas e das figuras, mas pode-se inferir que optaram pelo processo de indicar, em cada uma das seções do percurso narrativo, todos os elementos concretos e abstratos que podem ser encontrados no texto. Sem dúvida, é uma alternativa válida de análise, pois parte de elementos presentes no próprio texto para se tentar depreender o percurso temático e o percurso figurativo.

Porém, para a análise deste estudo, optou-se por uma estratégia diferente, pois se deve levar em conta que o texto que está sendo analisado é um texto narrativo de ficção e, caracterizado em sua macroestrutura pela presença de elementos concretos como os personagens, sejam eles representados por seres humanos ou por elementos antropomorfizados.

Deve-se destacar, ainda, que, por se tratar de uma fábula, não se pretende apenas contar uma história, mas levar a uma reflexão moralizante através das ações mostradas no desenrolar da narração. Assim, na maioria dos casos, a fábula é um texto figurativizado.

Assim, no texto Mudanças Radicais Imutáveis, pode ser encontrado um narrador ausente da trama, que leva à sensação de que se trata de uma história confiável, pois é contada por alguém que está distanciado dos conflitos.

As figuras abastado comerciante (linha 01) e imponente mansão (linha 02), no texto, levam ao tema (7) conforto. Este tema, porém, vai entrar em disjunção com as figuras ferreiros (linha 05), malhos (linha 07), bigornas (linha 07), e ferraduras (linha 07), que remetem ao tema desconforto.

$\mathrm{Na}$ sequência, as figuras 1000 iens (linhas $10 \mathrm{e}$ 22 ), e contrato (linha 19) remetem ao tema acerto. Como resultado deste último, aparece também o tema silêncio (linha 24).

Mas acerto e silêncio entram em disjunção com as figuras ouvidos estourando (linha 25), e mesmo barulho de sempre (linha 26) que, por sua vez, levam ao tema desacerto.

$\mathrm{O}$ quadro VII ilustra os temas e as figuras encontradas na análise do texto.

Neste momento da análise, o analista já possui vários elementos para poder retornar à análise das estruturas fundamentais, com o objetivo de se chegar aos elementos mais abstratos e mais gerais do texto ou, em outras palavras, o aboutness.

\begin{tabular}{|c|c|}
\hline Figuras & Temas \\
\hline abastado comerciante (linha 01) & \multirow{2}{*}{ conforto } \\
\hline imponente mansão (linha 02) & \\
\hline ferreiros (linha 06) & \multirow{4}{*}{ desconforto } \\
\hline malhos (linha 07) & \\
\hline bigornas (linha 07) & \\
\hline ferraduras (linha 08) & \\
\hline 1000 iens (linhas 11 e 23 ), & \multirow{2}{*}{$\begin{array}{c}\text { Acerto } \\
\text { silêncio } \\
\text { (linha 24) }\end{array}$} \\
\hline contrato (linha 21) & \\
\hline ouvidos estourando (linha 27) & \multirow{2}{*}{ desacerto. } \\
\hline mesmo barulho de sempre (linha 28 ) & \\
\hline
\end{tabular}

Quadro VII. Percurso Figurativo e Percurso Temático

\subsubsection{Procedimentos de análise das estruturas fundamentais}

A opção de se fazer a análise das estruturas fundamentais depois da análise das estruturas narrativas e das estruturas discursivas encontra respaldo em Moraes e Guimarães (2008, p. 39):

Nas estruturas fundamentais encontram-se as categorias semânticas que ordenam os conteúdos do texto de maneira mais geral e mais abstrata. Para que possa compreender, entretanto, a o valor de cada categoria, há que se buscar elementos nos outros níveis mais concretos do texto.

Embora afirmem que a análise das estruturas fundamentais deva ser o primeiro passo para a construção do Percurso Gerativo de Sentido, pode-se observar que os autores não iniciam a sua análise determinando qual seria o elemento mais abstrato do texto, como faz, por exemplo, Barros (1999) (8), mas conduzem a análise para o final, depois de ter feito a análise das demais estruturas, narrativas e discursivas. Deve-se observar que, no texto, não há nenhuma indicação que isto possa ser feito, bem como não há justificativas para deixar para o final a análise das estruturas fundamentais.

Assim, para se determinar as estruturas fundamentais há que se determinar o par fundamental subjacente ao texto. No caso do texto Mudanças Radicais Imutáveis, a categoria semântica fundamental é:

\section{Alteração vs. Permanência}

Estas categorias são sugeridas pela análise dos demais elementos do texto, como se pode ver anteriormente, como os temas acerto e desacerto. 
Desta forma, pode-se chegar, então, ao que se chama o aboutness do texto, que poderia ser sintetizado pelo par opositor alteração x permanência.

Várias passagens do texto assinalam positivamente para esta conclusão. Ao se verificar, por exemplo, a moral da história, pode-se verificar que os adjetivos esquerda e direita, utilizados nas expressões ferreiro da esquerda e ferreiro da direita, passam para a classe gramatical dos substantivos - a esquerda e a direita, usados correntemente como indicadores de posições políticas. Assim, a conclusão indicada por Moraes e Guimarães (2008, p. 43) é parcialmente correta, pois o texto trata de questões políticas, mas trata especificamente da imutabilidade destas posições, por mais que haja súplicas e pedidos por parte dos que se sentem incomodados.

Por fim, podem-se indicar, também, os meanings do texto, sugeridos pela análise das partes do texto. Pode-se, por exemplo, considerar os temas encontrados no percurso temático, feito durante a análise das estruturas discursivas: conforto, desconforto, acerto, desacerto.

Além destes, pode o analista escolher outros termos que se fizerem necessários para que o usuário de sua unidade de informação possa ter um acesso facilitado ao texto, mesmo que isto inclua descrições do gênero, como sátira política, por exemplo. Adentrando especificamente no terreno da identificação de conteúdo dos textos narrativos de ficção, como subsídio, principalmente, às atividades de indexação, surge a proposta de se analisar de que maneira a questão do aboutness se articula em textos dessa natureza. Para tanto, apresenta-se a proposta de se utilizar os parâmetros do Percurso Gerativo de Sentido, em seus três patamares, como elemento instrumental que pode auxiliar nesse processo.

\section{Considerações finais}

Como demonstrado, o textos narrativos de ficção também possui alguns elementos estruturais que podem ser considerados constantes, o que em muito pode facilitar a atuação do analista ao buscar o aboutness destes textos.

Assim, há uma superestrutura que pressupõe haver neste tipo de texto o predomínio das ações, bem como uma sequência de acontecimentos que envolvem a complicação, a avaliação e a resolução.

Além disso, o analista também se pode valer das estruturas narrativas para localizar a manipulação, a competência, a performance, a san- ção cognitiva, e a sanção pragmática, elementos constitutivos da chamada sequência canônica das estruturas narrativas, segundo item de análise do Percurso Gerativo de Sentido.

Neste momento, é interessante destacar-se que se pode forjar uma aproximação entre a questão da superestrutura, postulada por Van Dijk, e as estruturas narrativas, postuladas por Greimas. Ambas podem servir como ferramentas ao analista no processo de identificação do aboutness em textos narrativos de ficção. A primeira fornece elementos concretos e consistentes para identificação da forma do texto, confirmando-o como um texto narrativo; a segunda, permite ao analista identificar porções do texto que são mais ou menos constantes neste tipo de texto. Embora, como afirmado anteriormente, nem todos os elementos da sequência canônica apareçam obrigatoriamente no texto, algumas partes podem ser subentendidas, geralmente a porção inicial, manipulação, e a final, sanção, estão presentes durante a análise como já pode ser visto em outras análises do gênero.

Deve-se mencionar, também, as macroestruturas como elemento de análise dos textos narrativos de ficção. Como visto, nela podem ser identificados a presença de personagens, sejam humanos ou antopromorfizados, bem como uma ideia de ação, de mudança de estado, de transformação ou acontecimentos, nos quais a sequência temporal é fundamental.

O analista pode se servir, também, das estruturas discursivas para estabelecer critérios de análise, identificando os temas e as figuras presentes no texto para, em seguida, proceder-se ao percurso temático e ao percurso figurativo dos textos, elementos que auxiliam a depreensão do aboutness.

Da mesma forma que se forjou uma aproximação entre as superestruturas e as estruturas narrativas, pode-se fazer uma vinculação entre a microestrutura e as estruturas discursivas. $\mathrm{Na}$ primeira, tem-se a organização da estrutura linguística do texto, resultando desta ordenação a coerência do texto. As segundas, apresentam certa relação por indicarem se o texto é composto basicamente de elementos concretos figuras, e a quais elementos abstratos estes elementos remetem; por outro lado, os elementos abstratos - os temas, por sua vez, também constituem um percurso que pode remeter, por sua vez, a elementos concretos.

Há ainda que se considerar a análise das estruturas fundamentais com a questão do aboutness. Se considerar-se que nas primeiras encontram-se as categorias semânticas que ordenam os conteúdos do texto de maneira 
mais geral e mais abstrata, e que no segundo é encontrado o conteúdo intrínseco do texto podese estabelecer certa similaridade entre estes conceitos. O primeiro conceito preocupa-se com a questão semântica que dá origem ao processo de significação, ou seja, o elemento fundamental e primário, e que estabelece as suas relações em termos de valores, ou seja, a determinação da significação não é dada a priori, mas estabelecida em termos de relação. $\mathrm{O}$ foco, como dito, está no processo de estabelecimento da significação.

O segundo conceito busca tratar daquele elemento basilar sobre o qual se constrói o texto, também sendo observado em termos de relações, pois é a partir destas que se pode estabelecer os meanings, ou atribuições de significação a partir de um contexto de uso. O foco, neste caso, está no processo de inserção de um documento em um sistema com vistas à recuperação da informação.

Desta forma, embora com focos e áreas de aplicação bastante diferentes, há como se fazer uma aproximação entre estes dois conceitos, tendo em vista o interesse precípuo deste estudo, ou seja, o de se estudar formas de chegar até o aboutness dos textos narrativos de ficção.

Em outras palavras, o estabelecimento das estruturas fundamentais, considerando-se que esta é determinada pela oposição de dois termos, como disposto no quadrado semiótico de Greimas, pode levar ao que se entende por aboutness, aqui entendido como o conteúdo intrínseco ao texto.

Se o problema inicial era a proposição de um modelo metodológico que pudesse levar à depreensão do aboutness de textos narrativos de fiç̧ão, pode-se afirmar que este estudo pode chegar a seu termo, uma vez que indicou caminhos para o analista trabalhar com este tipo especial de texto.

\section{Notas}

(1) Sobre a questão da leitura técnica, vejam-se, dentre outros: Albrechtsen (1993), Cesarino e Pinto (1980), Chaumier (1980, p. 42-7), Cintra (1987) y Fujita. (1999a, 1999b, 2003a, 2003b, 2007).

(2) Segundo o Dicionário Houaiss online, a onomatopeia pode ser definida como a "formação de uma palavra a partir da reprodução aproximada, com os recursos de que a língua dispõe, de um som natural a ela associado."

(3) "The same document can have different meanings for the same reader at different times, but the document, itself unchanging, is assumed to possess a fundamental aboutness." (Beghtol, 1986, p. 85).

(4) Entendidas aqui como "mudanças de estado em termos de conjunção e disjunção (...) em termos de estruturas canônicas: manipulação, competência, performance e sanção". (Moraes; Guimarães, 2008, p. 39).

(5) "As estruturas narrativas abstratas (...) podem ser concretizadas através da figurativização ou da tematização, ou seja, através de temas ou figuras". (Moraes e Guimarães, 2008, p. 40).

(6) Tal concepção parece ir contra o espírito da Literatura, ou seja, de experimentar para pode conceber novas formas de narrar o mundo.

(7) Considerando-se que existe uma similaridade terminológica entre a porção abstrata dos textos (temas), e o resultado da extração do conteúdo de um texto (também chamado de tema, tematicidade, atinência, sobrecidade, aboutness), deve-se esclarecer que, neste momento da análise tema representa apenas a porção abstrata do percurso temático, em contraste com a posição concreta manifestada pelas figuras e pelo percurso figurativo.

(8) Nesta obra a autora faz a análise da canção infantil História de uma gata, de Luiz Henriquez, Sérgio Bardoti e Chico Buarque de Hollanda, e do poema Psicanálise do açúcar, de João Cabral de Melo Neto.

\section{Referências}

Albrechtsen, H. (1993). Subject analysis and indexing: from automated indexing to domain analysis. // The Indexer. 18:4 (October 1993) 219-224.

Beghtol, C. (1995). Domain analysis, literary warrant, and consensus: the case of fiction studies. // Journal of the American Society for Information Science. 46:1 (1995) 30-44.

Beghtol, C. (1986). Bibliographic classification theory and text linguistics: aboutness analysis, intertextuality and the cognitive act of classifying documents. // Journal of Documentation. 42:2 (June 1986) 84-113.

Beghtol, C. (1992). Toward a theory of fiction analysis for information storage and retrieval. // Williamson, N.J.; Hudon, M. Classification research for knowledge representation and organization. Amsterdam: Elsevier, 1992.

Beghtol, C. (1994). The classification of fiction: the development of a system based on theoretical principles. Metuchen, NJ: Scarecrow Press, 1994.

Beghtol, C. Stories: applications of narrative discourse analysis to issues in information storage and retrieval. // Knowledge Organization. 24:2 (1997) 64-71.

Cesarino, M. A. N.; Pinto, M. C. M. F. 1980. Análise de assunto. // Revista de Biblioteconomia de Brasília. 8:1 (jan./jun. 1980) 32-43.

Chaumier, J. (1980). Travail et methodes du/de la documentaliste: connaissance du problème. Paris : ESF/Libraries Techniques, 1980. Exposé 3, Chap.3: L'indexation.

Chaumier, J. Indexação: conceito, etapas e instrumentos. // Revista Brasileira de Biblioteconomia e Documentação. 21:1/2 (jan./jun. 1988) 63-79.

Cintra, A.M.M. (1987). Estratégias de leitura em documentação. // Smit, J. W. Análise documentária: a análise da síntese. Brasília: IBICT, 1987. 27-35.

Eriksson, R. The classification and indexing of imaginative literature. (2005). // Paper from the 16th ASIS\&T SIG/CR Classification Research Workshop, Charlotte: NC, October 29, 2005

Fernandes, M. (s. F.). Mudanças radicais imutáveis. // Fábulas Fabulosas. http://www2.uol.com.br/millor/fabulas/ 034.htm, no dia 24/05/2011).

Fujita, M. S. L. (1999a). Análise e síntese documentárias para compreensão de leitura de textos didáticos: uma proposta de aplicação do sistema de indexação Precis. 
// Informare: Cadernos do Programa de Pós-Graduação em Ciência da Informação. 5:2 (1999a).

Fujita, M. S. L. (1999b). A leitura do indexador: estudo de observação. // Perspectivas em Ciência da Informação. 4:1 (jan./jun 1999b) 101-116.

Fujita, M. S. L. (2003). A leitura documentária do indexador: aspectos cognitivos e lingüísticos influentes na formação do leitor profissional. 2003b. 321 f. Tese (Livre-Docência em Análise Documentária e Linguagens Documentárias Alfabéticas) - Faculdade de Filosofia e Ciências, Universidade Estadual Paulista, Marília, 2003.

Fujita, M. S. L. (2003a). A identificação de conceitos no processo de análise de assunto para indexação. // Revista Digital de Biblioteconomia e Ciência da Informação. 1:1 ( jul. 2003a).

Fujita, M. S. L. (2007). La enseñanza de la lectura documentaria en el abordaje cognitivo y socio-cognitivo: orientaciones a la formación del indizador. // Anales de Documentación. 10 (2-7) 1-16.

Garcia-Marco, F. J.; Moraes, J. B. E.; Garcia-Marco, L. F.; Guimarães, J. A. C. (2010). Knowledge organization on fiction and narrative documents: a challenge in the age of multimedia revolutions. // Gnolli, C.; Mazzocchi, F. (Org.). Paradigms and conceptual systems in knowledge organization. Würzburg: Ergon, 2010. 262-268.

García-Marco, L. F.; García-Marco, F .J. (1997). El resumen de documentos literarios narrativos: algunas propuestas metodológicas. // Organización del Conocimiento en Sistemas de Información y Documentación. 2 (1997) 73-85.

Guimarães, J. A. C.; Moraes, J. B. E.; Guarido, M. D. M. (2007). Análisis documental de contenido de textos narrativos: bases epistemológicas y perspectivas metodológicas. // García Marco, F. J. (Org.). Avances y perspectivas en sistemas de información y documentación en entorno digital. Zaragoza: Prensas Universitarias de Zaragoza, 2007. 93-100.

Hayes, S. Enhanced catalog access to fiction: a preliminary study. // Library Resources \& Technical Services. 36:4 (1992) 441-59.

Koch, I.G.V.; Fávero, L.L. (1987). Contribuição a uma tipologia textual. // Letras e Letras. 3:1 (1987) 3-10.

Moisés, M. (2009). Dicionário de Termos Literários. São Paulo: Cultrix, 2009

Moraes, J. B. E. (2008). Análise documental de crônicas: reflexões sobre uma trajetória de interlocução entre literatura, linguística e ciência da informação. // Guimarães, J. A. C; Fujita, M. S. L. Ensino e pesquisa em Bibliote- conomia no Brasil: a emergência de um novo olhar. São Paulo: Editora Cultura Acadêmica, 2008. 129-144.

Moraes, J. B. E.; Guimarães, J. A. C. (2008). Análise documental de conteúdo de textos literários narrativos: em busca de um diálogo entre as concepções de aboutness/meaning e percurso temático/percurso figurativo. // Gaspar, N. R.; Romão, L. M. S. Discurso e Texto: multiplicidade de sentidos na Ciência da Informação. São Carlos : EDUFSCar, 2008, 35-45.

Moraes, J. B. E.; Guimarães, J.A.C. (2006). Análisis documental de contenido de textos literarios narrativos: en busca del diálogo entre las concepciones de aboutness/meaning y de recorrido temático/recorrido figurativo. // Scire. 12 (2006) 71 - 84.

Nielsen, H. J. (1997). The nature of fiction and its significance for classification and indexing. // Information Services \& Use. 17: 2-3 (1997) 171-181.

Pejtersen, A.M. (1978). Fiction and library classification. // Scandinavian Public Library Quarterly. 1 (1978) 5-12.

Pejtersen, A.M. (1979). The meaning of 'about' in fiction indexing and retrieval. // Aslib Proceedings. 31:5 (May, 1979) 251-257.

Pejtersen, A.M.; Albrechtsen, H.; Sandelin, R.; Lundgren, L.; Valtonen, R. (1998). The Scandinavian book house: indexing methods and OPAC development for subject access to Scandinavian fiction literature. // Advances in classification research. 6 (1998) 99-113.

Pejtersen, A.M.; Austin, J. (1983). Fiction retrieval: experimental design and evaluation of a search system based on users' value criteria: part 1. // Journal of Documentation. 39:4 (1983) 230-246.

Pejtersen, A.M.; Austin, J. (1984). Fiction retrieval: experimental design and evaluation of a search system based on users' value criteria: part 2. // Journal of Documentation. 40: 1 (1984) 25-35.

Quinelato, E. (2009). A figurativização do trabalho nas fábulas de Esopo. Araraquara: Universidade Estadual Paulista, Faculdade de Ciências e Letras 2009. 195 f. Tese (doutorado em Estudos Literários).

Saarti, J. (1999). Fiction indexing and the development of fiction thesauri. // Journal of Librarianship and Information Science. 31:2 (1999) 85-92.

Van Dijk, T. (1997). La ciencia del texto: un enfoque interdisciplinario. Barcelona: Paidós, 1997.

Enviado: 2012-04-16. Versión corregida: 2012-07-16 Aceptado: 2012-08-02. 